\title{
Childhood Poisoning at a Tertiary Hospital in South West Nigeria
}

\author{
Olatunya $\mathrm{OS}^{1}$, Isinkaye $\mathrm{AO}^{2}$, Ogundare $\mathrm{EO}^{3}$, Oluwayemi $\mathrm{IO}^{4}$, Akinola $\mathrm{FJ}^{5}$
}

\begin{abstract}
Introduction: Poisoning is a preventable cause of childhood morbidity and mortality. Information on childhood poisoning in the developing world is scanty. This study describes the profile of childhood poisoning in a third world hospital. Materials and Methods: Children admitted with poisoning over a 48-months period at the Ekiti State University Teaching Hospital Ado-Ekiti, Southwest Nigeria, were reviewed. Results: It was found that 81 of 5256 admissions representing $1.54 \%$ of the total admissions were due to poisoning. Kerosene, Drugs, Alcohol based herbal concoction, pesticides, corrosive agents and carbon monoxide were involved in $37.0 \%, 22.2 \%, 19.8 \%, 8.6 \%, 6.2 \%$ and $6.2 \%$ respectively. Accidental and non-accidental intentions were involved in $85.2 \%$ and $14.8 \%$ cases respectively. Administration of palm oil (oil from Elais guineensis), vomiting induction and herbal concoction were the leading home interventions in $69.1 \%, 38.3 \%$ and $23.5 \%$ respectively. One patient required intensive care. There were seven deaths and overall mortality rate was $8.6 \%$. Conclusion: Poisoning remains a cause of childhood morbidity and mortality in Nigeria. Establishment of poisoning information and control centre is recommended among other strategies to combat its scourge.
\end{abstract}

Key words: Childhood poisoning, Child deaths, Southwest, Nigeria

\section{Introduction}

$\mathrm{P}$ oisoning in children is a preventable cause of morbidity and mortality that is still very common worldwide ${ }^{1}$. The developed countries of the world are containing it through adequate data gathering and other well entrenched institutionalised policies ${ }^{2,3,4,5}$. In contrast, poisoning profiles in developing countries are poorly documented ${ }^{6,7}$. The high contributions of malnutrition and infectious diseases to the overbearing burden of childhood morbidity and mortality in these countries have the tendency to divert attention from other preventable causes of child deaths ${ }^{8}$. There are few studies from Nigeria on childhood poisoning, $9,10,11,12,13,14,15$ some of them were restricted to a few targeted poisoning agents ${ }^{9,10}$ while some are quite dated ${ }^{11,12}$ and none was from the current study area. This paper examines childhood poisoning at a tertiary hospital in south west Nigeria. The study was conducted with the aims of
'Oladele Simeon OLATUNYA, Lecturer, Department of Paediatrics, Ekiti State University/ Teaching Hospital, Ado Ekiti, Ekiti State, Nigeria, ${ }^{2}$ Ayodeji Olusola Isinkaye, Federal Medical Centre Ido Ekiti, Department of Community Medicine, Nigeria, ${ }^{3}$ Ezra Olatunde Ogundare, Dept of Paediatrics, Ekiti State University/Teaching Hospital, Ado Ekiti, Nigeria, ${ }^{4}$ Isaac Oludare Oluwayemi, Department of Paediatrics, Ekiti State University Teaching Hospital, Nigeria, ${ }^{5}$ Foluso John Akinola, Department of Paediatriics, Ekiti State University Teaching Hospital, Nigeria.

\section{Address for correspondence:}

Dr. OLATUNYA Oladele Simeon

Department of Paediatrics

Ekiti State University/Teaching Hospital

P.O. BOX, 2267, Ado Ekiti, Ekiti State, Southwest Nigeria

Tel +2348038617705

E-mail: ladeletunya@yahoo.com

\section{How to cite}

Olatunya OS, Isinkaye AO, Ogundare EO, Oluwayemi IO, Akinola FJ. Childhood Poisoning at a Tertiary Hospital in South West Nigeria. J Nepal Paediatr Soc 2015;35(2):103-110.

doi: http://dx.doi.org/10.3126/jnps.v35i2.12548

This work is licensed under a Creative Commons Attribution 3.0 License.

\section{(c) (7)}

identifying the demographic features of children involved with poisoning, their clinical features, types of poisoning agents, home interventions and the outcome of hospital treatment. Information from the current study will update data on childhood poisoning in Nigeria and help stakeholders in planning appropriate preventive and management strategies. 


\section{Material and Methods}

This study was conducted at The Ekiti State University Teaching Hospital (EKSUTH), Ado Ekiti, the capital of Ekiti State in South west Nigeria. The hospital receives referrals from public and private hospitals within the state and from neighbouring towns in other adjoining states like Ondo, Osun, Kogi and Kwara. New paediatric patients are usually first seen at the paediatric out-patient department (POPD) before being triaged. The POPD and the children emergency ward (CEW) are both housed in the same building. They are co-managed as a joint entity by six doctors and fifteen nurses. These are made up of five paediatric registrars, three paediatric nurses, twelve nurse-midwives and a supervising consultant paediatrician. Records of all children admitted into the CEW of EKSUTH for poisoning between January 1, 2011 and December 31, 2014 were reviewed. A pre-tested review chart form was used to extract information on patients' socio-demographic characteristics, admission date, time poisoning occurred, poison agent, poisoning circumstances, duration of poisoning before presentation, home intervention(s), symptoms, hospital interventions, admission duration, outcome and number of follow up visit. Cases of poisoning from animal bites and food contamination were not included. Parental socio-economic status was determined using their occupation and levels of education ${ }^{16}$.

Approval for the study was obtained from the Ethics Committee of Ekiti State University Teaching Hospital. Statistical analysis was conducted with IBM SPSS software version 20. Descriptive statistics were performed using simple proportions while Fisher's exact test was carried out to detect relationship between variables.

\section{Results}

A total of 5,256 children were admitted into the Children Emergency ward (CEW) during the study period. Eighty-one (81) of them, representing 1.54\% were cases of child poisoning. They were made up of 47 (58.0\%) boys and 34 (42.0\%) girls. Their median age was 36 months with a range from six weeks to 15 years. Most of the children, 53 (65.4\%) were between one and five years of age, followed by those aged above five years, 20 (24.7\%), while the remaining $8(9.9 \%)$ were aged less than one year. The children were more or less evenly distributed across the three family social classes with 25 (30.9\%), 27 (33.3\%) and $21(25.9 \%)$ belonging to the lower, middle and upper classes respectively. Eight $(9.9 \%)$ of the children had no documented information necessary for computing their family social classes.

Regarding the circumstances surrounding poisoning incidence and home interventions given before presentation at the hospital, 69 (85.2\%) of the cases of poisoning in the patients were accidental and the ages of patients with accidental poisoning ranged between six months and 84months with a mean of 36 months. This is followed by twelve (14.8\%) intentional poisoning that included three suicidal attempt cases. The patients with intentional poisoning were aged between 10 and 15 years with a mean age of 12.8 years. None was homicidal. Most of the poisoning cases $76(93.8 \%)$, occurred during the day and majority $72(88.9 \%)$, took place at home. The largest proportion of the children (25.9\%), ingested the poisoning agents kept in used water bottles. Most of the poisoning agents were kept at home in the living room (50.6\%) and the kitchen (18.5\%).

Poisoning occurred as a results of self-ingestion by $65(80.2 \%)$ of the children, three of which were cases of attempted suicide by adolescent girls aged 13, 14 and 15 years who had ingested sodium hypochlorite solution, a rodenticide (pesticide) and a corrosive agent respectively following disagreements with their parents. Two of them had psychiatric evaluation done by the mental health physicians. Patient's mother administered the poisoning agents in six (7.4\%) cases, grandmother and other close relatives in four (4.9\%) cases, and a crèche's member of staff in one (1.2\%) case. The remaining five $(6.2 \%)$ children were cases of inhalation of emissions from electricity generating sets while sleeping. There were no cases of ingestion of multiple agents. Palm oil (oil from Elais guineensis) was the commonest home remedy administered in 56 (69.1\%) cases, followed by induced vomiting (38.3\%), herbal concoctions (23.5\%), milk (4.9\%) and enema (3.7\%) Table1. The mean duration before presenting at the hospital after poisoning, was $7.9 \pm 8$.3hours (range 30 minutes to 3 days) with 20 (24.7\%), 55 (67.9\%), and $6(7.4 \%)$ patients presenting within 6 hours, between 6 to 12 hours, and at greater than 12 hours respectively.

Table 1: Poisoning circumstances and home intervention

\begin{tabular}{|l|c|c|}
\hline & Frequency & Percent \\
\hline Circumstance of poisoning & & \\
\hline Accidental & 69 & 85.2 \\
\hline Intentional & 12 & 14.8 \\
\hline Place of poisoning & & \\
\hline Home & 72 & 88.9 \\
\hline
\end{tabular}




\begin{tabular}{|c|c|c|}
\hline Neighbour's / Parent's shop & 4 & 4.9 \\
\hline Farm & 3 & 3.7 \\
\hline Mother's workplace & 1 & 1.2 \\
\hline Crèche & 1 & 1.2 \\
\hline \multicolumn{3}{|l|}{ Poison container } \\
\hline $\begin{array}{l}\text { Polyethylene terephthalate } \\
\text { (PET) water bottle }\end{array}$ & 21 & 25.9 \\
\hline Soft drink/beer/wine bottle & 19 & 23.5 \\
\hline $\begin{array}{l}\text { Medicine bottle / Product } \\
\text { container }\end{array}$ & 14 & 17.3 \\
\hline Others (envelope, food, etc) & 14 & 17.3 \\
\hline $\begin{array}{l}\text { Household utensils (cup, bowl, } \\
\text { etc) }\end{array}$ & 5 & 6.2 \\
\hline Unspecified bottle & 2 & 2.5 \\
\hline No information & 6 & 7.4 \\
\hline \multicolumn{3}{|l|}{ Storage of poisoning agent } \\
\hline Living room & 41 & 50.6 \\
\hline Kitchen & 15 & 18.5 \\
\hline Office / shop & 5 & 6.2 \\
\hline Cabinet / cupboard & 3 & 3.7 \\
\hline Farm & 3 & 3.7 \\
\hline Laundry & 3 & 3.7 \\
\hline No information & 11 & 13.6 \\
\hline \multicolumn{3}{|l|}{ Poison administration } \\
\hline Self & 65 & 80.2 \\
\hline Mother & 6 & 7.4 \\
\hline Inhalational & 5 & 6.2 \\
\hline Grandmother / other relatives & 4 & 4.9 \\
\hline Crèche staff & 1 & 1.2 \\
\hline \multicolumn{3}{|l|}{ Home remedies given } \\
\hline Palm oil & 56 & 69.1 \\
\hline Vomiting induced & 31 & 38.3 \\
\hline Herbal concoction & 19 & 23.5 \\
\hline None & 18 & 22.2 \\
\hline Milk & 4 & 4.9 \\
\hline Enema & 3 & 3.7 \\
\hline
\end{tabular}

Table 2: Symptoms and Hospital interventions

\begin{tabular}{|l|c|c|}
\hline Symptoms in patients & Frequency & Percent \\
\hline Dyspnoea & 50 & 61.7 \\
\hline Cough & 35 & 43.2 \\
\hline Fever & 25 & 30.9 \\
\hline Unconsciousness & 20 & 24.7 \\
\hline Seizure / Convulsion & 15 & 18.5 \\
\hline Weakness / Lethargy & 15 & 18.5 \\
\hline Vomiting & 10 & 12.3 \\
\hline Irrational behaviour & 4 & 4.9 \\
\hline No symptoms & 4 & 4.9 \\
\hline Saliva drooling & 3 & 3.7 \\
\hline
\end{tabular}

\begin{tabular}{|l|c|c|}
\hline General body pains & 3 & 3.7 \\
\hline Refusal of feeds & 2 & 2.5 \\
\hline Excessive cry & 1 & 1.2 \\
\hline Investigations requested & & \\
\hline Full blood count & 59 & 72.8 \\
\hline $\begin{array}{l}\text { Serum electrolyte, urea and } \\
\text { creatinine }\end{array}$ & 51 & 63.0 \\
\hline Random blood sugar & 38 & 46.9 \\
\hline Chest X-ray & 35 & 43.2 \\
\hline PCV only & 20 & 24.7 \\
\hline Malaria parasite & 15 & 18.5 \\
\hline Treatment administered & & \\
\hline Intra-venous fluids & 55 & 67.9 \\
\hline Antibiotics & 54 & 66.7 \\
\hline Intra-nasal oxygen & 42 & 51.9 \\
\hline Antimalarials & 15 & 18.5 \\
\hline Anti-convulsant & 8 & 9.9 \\
\hline Gastric lavage & 6 & 7.4 \\
\hline Observation & 3 & 3.7 \\
\hline Blood transfusion & 2 & 2.5 \\
\hline Duration of admission (days) & & \\
\hline 1 day or less & 24 & 29.6 \\
\hline 1 - 3 days & 15 & 49.4 \\
\hline$>3$ days & 2.5 \\
\hline No information & & 2.5 \\
\hline Number of follow-up visits & & \\
\hline None & & 77.8 \\
\hline Once & & 17.3 \\
\hline Twice & & 14.7 \\
\hline No information & & \\
\hline
\end{tabular}

Respiratory system related symptoms of dyspnoea $(61.7 \%)$ and cough (43.2\%) constituted the commonest presenting complaints. Haemograms and serum electrolytes were the most common investigations requested in the cases. None of the case had toxic levels of agents assayed as there were no facilities to do so. Intravenous fluids (67.9\%), antibiotics (66.7\%), and intranasal oxygen (51.9\%) were the common hospital intervention administered. Most patients, 40 (49.4\%) were on hospital admission for 24 - 36 hours and only 15 (18.5\%) returned for at least one follow-up visit (Table 2).

Most of the cases, 69 (85.2\%) recovered fully, five $(6.2 \%)$ discharged against medical advice (DAMA) and seven children died. This is equivalent to a case fatality rate of $8.6 \%$. The results of bivariate analysis for relationship between poisoning agent and age and patient outcome are shown in Table 3. Kerosene was the commonest poisoning agent (37.0\%), followed 
Table 3: Poisoning Agent by Age and Outcome

\begin{tabular}{|c|c|c|c|c|c|}
\hline \multirow[t]{2}{*}{ Type of poison } & \multicolumn{3}{|c|}{ Age (years) } & \multirow[t]{2}{*}{ Total } & Fisher's exact $\mathbf{P}$ \\
\hline & $<1$ & $1-5$ & $>5$ & & \multirow{7}{*}{0.000} \\
\hline Kerosene & $0(0.0)$ & $30(56.6)$ & $0(0.0)$ & $30(37.0)$ & \\
\hline Drugs $^{\dagger}$ & $3(37.5)$ & $12(22.6)$ & $3(15.0)$ & $18(22.2)$ & \\
\hline Alcohol based Herbal concoction & $5(62.5)$ & $2(3.8)$ & $9(45.0)$ & $16(19.8)$ & \\
\hline Pesticides / Herbicides & $0(0.0)$ & $5(9.4)$ & $2(10.0)$ & $7(8.6)$ & \\
\hline Caustic soda (NaOH) & $0(0.0)$ & $3(5.7)$ & $2(10.0)$ & $5(6.2)$ & \\
\hline Carbon monoxide & $0(0.0)$ & $1(1.9)$ & $4(20.0)$ & $5(6.2)$ & \\
\hline \multirow[t]{3}{*}{ Total } & $8(100.0)$ & $53(100.0)$ & $20(100.0)$ & $81(100.0)$ & \\
\hline & \multicolumn{3}{|c|}{ Outcome } & & \\
\hline & Recovered & DAMA & Died & Total & Fisher's exact $\mathbf{P}$ \\
\hline Kerosene & $26(37.7)$ & $2(40.0)$ & $2(28.6)$ & $30(37.0)$ & \multirow{6}{*}{0.878} \\
\hline Drugs $^{\dagger}$ & $16(23.2)$ & $1(20.0)$ & $1(14.3)$ & $18(22.2)$ & \\
\hline Alcohol based Herbal concoction & $13(18.8)$ & $1(20.0)$ & $2(28.6)$ & $16(19.8)$ & \\
\hline Pesticides / Herbicides & $6(8.7)$ & $0(0.0)$ & $1(14.3)$ & $7(8.6)$ & \\
\hline Caustic soda (NaOH) & $4(5.8)$ & $1(20.0)$ & $0(0.0)$ & $5(6.2)$ & \\
\hline Carbon monoxide & $4(5.8)$ & $0(0.0)$ & $1(14.3)$ & $5(6.2)$ & \\
\hline Total & $69(100.0)$ & $5(100.0)$ & $7(100.0)$ & $81(100.0)$ & \\
\hline
\end{tabular}

+ Includes: Antimalarial tablets and syrup, ferrous tabs, salbutamol syrup, griseofulvin, oral hpoglycemics, anti hypertensives, ciproheptadine, Nathpthalene and methylated spirit.

$\ddagger$ Discharged against medical advice

by drugs (22.2\%), alcohol based concoctions (19.8\%), pesticides / herbicides (8.6\%), caustic soda (6.2\%) and carbon monoxide (6.2\%). Infants were more likely to have poisoning from alcohol based concoctions (Fisher's exact $p<0.001$ ). There was no statistically significant association between patient outcomes and poisoning agents (Fisher's exact $p>0.05$ ).

Of the seven children that died, one (a ten month old boy) was forcefully administered with overdose of unspecified anti-malarial syrup by a caregiver at the crèche. He was admitted with dyspnoea noticed immediately after the drug administration, fever, unconsciousness, coarse crepitations, severe anaemia (haematocrit was 14\%) and malaria parasitaemia but died about one and half hours later while undergoing blood transfusion. A second 10 month old boy who was administered with herbal concoction by his grandmother presented three days after with seizures, unconsciousness and dyspnoea. He had received palm oil, enema and more herbal concoctions as home remedies but died within 48 hours of admission.

The third and fourth mortalities were cases of self-ingestion of kerosene by two boys aged 15 and 22 months. They presented with unconsciousness, focal seizures, dyspnoea, hypoglycaemia and malaria parasitaemia. Each of them died within 20 hours of admission. The fifth case involved a 3 year old boy who accidentally self-ingested an organophosphate pesticide (Gamalin-20, the trade name of a popular organophosphate based pesticide used by farmers in Nigeria) on the farm. He presented 18 hours later at the hospital with dyspnoea, fever, seizures and unconsciousness after receiving some herbal concoction, palm oil and induced vomiting at home. He also died within 20 hours of admission. The sixth case involved a four year old girl (as well as her mother) who had carbon monoxide poisoning from exhaust fumes from an electricity generating set placed overnight near their window. They were brought to the hospital by neighbours more than ten hours after exposure. She presented unconscious and died within six hours of admission.

The last case was a twelve year old boy who ingested a locally available alcohol-based aphrodisiac herbal mixture, Osomo $^{\circledR}$ kept at home by his stepfather. He presented at the hospital after 16 hours with dyspnoea, unconsciousness and seizures. He was discharged against medical advice by his caregivers after three days of admission and got re-admitted two days later with features of acute renal failure alongside his earlier signs and symptoms. He died within twentyfour hours of his re-hospitalization at the intensive care unit while being worked up for haemodialysis. 


\section{Discussion}

The determinants of poisoning outcome in children includes: the physiology of the child, child's health status, type of agents involved, duration of symptoms before presentation and the quality of care received $^{6,7,17}$. In this study, $1.54 \%$ of all admissions at the CEW were due to poisoning. This proportion is higher than $0.2 \%$ to $0.94 \%$ previously reported from hospital based studies in Nigeria ${ }^{11,12,13,15}$. It is an indication that the burden of childhood poisoning is high in the study area.

Except for the even distribution of the patients across the social divides in the current study, other demographic attributes of the patients as found, had been described locally $9,10,11,12,13,14$. and internationally $2,3,6,7,18,19,20$. This attests to the global similarities in the demographic picture of children with poisoning. The referral status of the current study centre, coupled with the metropolitan nature of the study centre location could have been responsible for the observed social class admixture as previous Nigerian studies indicated a higher preponderance of childhood poisoning in the lower class ${ }^{9,10,11,12,13,14,15}$. Our findings could also be a hint at possible changes in the epidemiology of the condition in the country. Although one study from Nigeria ${ }^{15}$ found a female preponderance, other Nigerian and international studies are in agreement with the male preponderance observed in this study $2,6,7,11,12,13,19,20$. Also, the observation that most cases were unintentional, especially among the under-fives, is not restricted to this study $2,3,4,5,6,7,7,9.10,11,12$, $13,14,15$. Children in this age group are in their formative years when they are usually more adventurous ${ }^{15,17,21}$ and so, may inadvertently ingest the agents. The bimodal nature of the cases in this study, with nonintentional poisoning involving young children and intentional cases involving adolescents, conforms with previous reports ${ }^{2,4,7,11,15}$. Intentional poisoning involving ingestion of poisonous substances with suicidal intent is especially noted with adolescents ${ }^{17,22,23}$. This tendency was thought to be peculiar to the developed world, but it is now being increasingly recognised in the third world $11,7,15,19$. These behaviours among adolescents could reflect their maladjustments as they transit to adulthood $23.24,25,26$. Two of the three adolescents girls with intentional poisoning for suicidal purposes in this review, had psychiatric evaluation conducted on them by mental health physicians.

Kerosene (paraffin), a dangerous hydrocarbon derived from petroleum distillates is the leading poisoning agent in this review and this conforms with some earlier Nigerian reports ${ }^{11,12}$. Similar trends have also been observed in neighbouring African countries ${ }^{6,27}$. In Nigeria, kerosene is a major source of household fuel used for cooking and lighting ${ }^{9,10,11,12,13,14,21}$. It is also stocked for business purposes by many traders and households in unmarked familiar containers that are usually very attractive to children. The high volatility of its vapour makes it diffuse readily to children's airway upon ingestion, thereby causing irritation of the airways ${ }^{17,21}$. This perhaps, explains the high proportion of patients with respiratory symptoms in this review.

There were higher preponderances of drugs and alcohol poisoning in this study compared to most Nigerian studies ${ }^{11,13,15}$. This may connote a gradual shift towards poisoning patterns in other parts of the world $d^{6,20-21}$ and may be a reflection of the double burden of childhood poisoning in the study area as epidemiology of poisoning varies with time and place $^{1,6,7,17,21}$. The incessant use of alcohol under the guise of herbal remedies among adult Nigerians ${ }^{28}$ might have contributed to this pattern as children like to copy adults ${ }^{17,21}$.

Like a previous Nigerian report where mortality was recorded ${ }^{15}$, one of the five cases of carbon monoxide (CO) poisoning in this review died. Until recently ${ }^{15}$, CO poisoning was rare in Nigeria ${ }^{11,12,13}$. The epileptic power supply bedevilling the country has led many households to depend on electricity generators for their power supply ${ }^{29}$ and this may fuel an upsurge in the number of new cases of $\mathrm{CO}$ poisoning if not checked. Most of these household generators are usually poorly maintained leading to their emission of CO from incomplete combustions. CO becomes hazardous when excessive accumulation occurs and its toxic threshold is reached or exceeded thereby causing health hazards. It displaces oxygen from its binding sites in haemoglobin to form Carboxy-haemoglobin (COHb) which impairs oxygen delivery to body tissues ${ }^{17,30}$. Expectedly, victims suffer tissue hypoxia and they often present with a barrage of symptoms ranging from headache, coma, convulsions and irregular breathing patterns ${ }^{15,17,30-31}$. Some of the cases of $\mathrm{CO}$ poisoning involved in this study were admitted with convulsions, coma and irregular breathings. The four surviving cases are being followed up for the manifestations of some recognised sequelae of $\mathrm{CO}$ poisoning which includes impaired cognition, progressive brain damage and chronic lung disease ${ }^{15,17,30,31}$.

The high rates of induction of vomiting and administration of herbal concoctions as home interventions reflects the poor knowledge of parents 
in the study area on the health dangers inherent in such practices ${ }^{6,11,17,21}$. Africans in rural settings still have strong faiths in the use of traditional herbal agents as home remedies in poisoning cases ${ }^{6,11}$ These agents have been found to contribute significantly to mortality in childhood poisoning ${ }^{6,11}$ The need for more education of parents on the use of only safe home interventions for children with poisoning cannot be overemphasised. One way of doing this, is through the establishment of poison information and control centres in the country where parents or caregivers can readily call to obtain information and seek advice on the poisoning situations involving their wards as obtainable in other countries $3,7,18,20$. The relatively high ownership rate of mobile telephones lines in Nigeria will readily support this services if adopted ${ }^{32}$. The use of jingles in mass media and regular counselling of caregivers on poisoning prevention during clinic visits are also recommended.

A critical look at the intervention in the hospital revealed that they consisted mostly of supportive care and ordering of routine investigations as none of the patients had assays of the toxic levels of the poisoning agents determined or their arterial blood gases measured where applicable. Also, antidotes were not given for some specific cases except for the five cases of $\mathrm{CO}$ poisoning. This could be attributable to the level of severity of the cases or non-availability of more advance tools for the care of poisoned children in the study area as stated. Inadequate knowledge on the part of the health professionals attending to the patients could also be a factor.

An appraisal of the other remaining deaths in this review, depict very interesting scenarios reflecting the turbulent milieu within which children in the developing world operate. For the ten month old child poisoned at the crèche, the constellation of the symptoms and signs suggests a child who had been unwell for quite some time but being forced to be cared for by an unskilled crèche member staff. She masqueraded as an health worker but could not identify the danger signs in the child only to finally pull the death trigger by giving overdose of drugs albeit forcefully. This case also highlights the impact of co-morbid conditions on the outcome of childhood poisoning ${ }^{6,17}$. In the cases of kerosene and direct herbal concoction poisonings, the deaths might be attributable to the high hazard factor of the agents they ingested ${ }^{6}$. The twelve year old boy might have been cajoled by the alleged mystical powers of the ingested herbal concoction as being touted in its many widely publicised adverts across the country as an herbal medicine and food supplement. In
Nigeria, herbal remedies are registered by The National Agency for Food, Drug Administration and Control (NAFDAC) for public consumption ${ }^{33}$. Although the ingested herbal remedy was not available for analysis in this review, nevertheless, studies have shown that some herbal remedies being marketed in Nigeria lack standardised methods of preparation as stipulated by standard international best practices ${ }^{28,34,35}$. As a result, they have wide variations in the contents of their active ingredients even within cohorts of the same batch and are laden with hazardous materials that are injurious to health ${ }^{28,34}$. These observations may not be totally divulged from the spectral of the clinical manifestations in the child before his demise. The patient with organophosphate ingestion and poisoning on the farm also reinforces the need for more education and enlightenment programmes for farmers on safe storage, usage and handling of herbicides and pesticides. This will prevent children from having easy access to chemicals used for agricultural purposes.

The $8.6 \%$ mortality rate in this study is higher than the $0.0 \%$ and $3.8 \%$ reported from Maiduguri ${ }^{13}$ and Jos ${ }^{15}$ in northern Nigeria, but lesser than $11.9 \%$ and $20.0 \%$ earlier reported in Ile-Ife ${ }^{11}$ and Calabar ${ }^{12}$ respectively both from the southern parts of the country where the current study was conducted. This may suggest a possible regional dichotomy and or, a decrease in the burden of childhood poisonings in the southern part of the country. However, these figures need to be interpreted with caution as the previous studies from southern Nigeria are quite older. Nevertheless, the mortality rate in the current study is far above what is being reported from other parts of the world $3,7,18,19,20$. This indicates the need for improved care and outcome for children with poisoning in the study area and Nigeria by extension. Upgrading implements for the care of children with poisoning and regular in-service trainings or refresher courses for health workers in the country will update them on current trends in poisoning management such as the use of Poison Scores to triage, classify and plan management of poisoning patients ${ }^{6,36}$.

\section{Conclusion}

This study has highlighted the burden of childhood poisoning in the study area and identified challenges facing its management. It also raises questions about factors that sustain the current status. Establishment of poison information and control centres, focused health education on rational use of drugs, herbal mixtures, and regulation of their sales with appropriate legislation will help combat the burden of childhood poisoning in developing countries. 
Acknowledgements: The authors appreciate the staffs of the records departments for helping to retrieve the patients` files.

Funding: Nil

Conflicts of interest: None

Permission from IRB: Yes

\section{References}

1. World Health Organisation/ UNICEF. World report on child injury prevention 2008 Available at http://whqlibdoc.who.Int/ publications/2008/9789241563574_eng.pdf Retrieved 20/01/2015.

2. McKenzie L, Ahir N, Stolz U, Nelson N. Household cleaning product - related injuries treated in US Emergency Departments in 1990 - 2006. Pediatrics 2010;126(3):509-16.

3. Robert L, Franklin MS, Gregory BR. Unintentional Child poisonings treated in United States Hospital Emergency Departments: National Estimates of incident cases, population- based poisoning rates and product involvement. Pediatrics 2008;122:1244-51.

4. Kivisto JE, Mattila V, Arvola T, Paavola M, Parkkari J. Secular trendsinpoisonings leading to hospital admission among finish children and adolescents between 1971 and 2005. J Pediatr 2007;219:25470 .

5. Riffat F, Cheng A. Pediatric caustic ingestion: 50 consecutive cases and a review of the literature. Dis Esophagus 2009;22(1):89-94.

6. Balme KH, Roberts JC, Glastone M, Curling L, Mann $M D$. The changing trends of childhood poisoning of a tertiary children's hospital in South Africa. $S$ Afr Med J. 2012:102(3):142-6.

7. Nowneet KB, Minakshi D, Sohaib A, Vipan C. Profile of poisoning in children and adolescents at a North Indian tertiary care centre. J Ind Acad Clin Med 2012;13(1):37-42.

8. State of the World Children 2013. Available at www. unicef.org/sowc2013. Retrieved 20/12/2014.

9. Fagbule DO, Joiner KT. Kerosene poisoning in childhood: a 6 - year prospective study at the University of Ilorin Teaching Hospital. West Afr J Med 1992;11(2):116-21.

10. Orisakwe OE, Egenti L, Orish C. Childhood nondrug poisoning in Nnewi, Nigeria. Trop Doct 2000;30(4):209- 11.

11. Adejuyigbe EA, Onayade AA, Senbanjo IO, Oseni SBA. Childhood Poisoning at the Obafemi Awolowo
University Teaching Hospital, Ile - Ife, Nigeria Niger J Med 2002;11(4):183-6

12. Ochigbo SO, Udoh JJ, Antia - Obong OE. Accidental Childhood poisoning in Calabar at the turn of the $20^{\text {th }}$ Century. Nig J Paed 2004;31(3):67-70.

13. Oguche S, Bukbuk DN, Watila IM. Pattern of hospital admissions of children with poisoning in the Sudano - Sahelian North Eastern Nigeria. Niger J Clin Pract 2006;10(2):111-15.

14. Belonwu RO, Adeleke SI. A Seven - year review of accidental kerosene poisoning in children at Aminu Kano Teaching Hospital, Kano. Niger J Med. 2008;17(4):380-82.

15. Shwe DD, Toma B, Pate SI, Adedeji I, Oguche S. Profile of Hospital Admissions of childhood poisoning at a North - Central Nigerian Tertiary Health care Centre. Jos J Med 2013;7(2):5-11.

16. Oyedeji GA. Socio - economic and cultural background of hospitalized children in Ilesha. Nig. J Paed. 1985;12:111-17.

17. O' Donnell KA, Ewald MB. Poisoning In: Kliegman RM, Staanton BF, ST. Geme JW, Schor NF, Behrman RE eds. Nelson Textbooks of Paediatrics $19^{\text {th }}$ edition, Elsevier publisher USA, 2011;250- 274.

18. Lamireau $T$, Llanas B, Kennedy A, Fayon $M$, Penouil JC, Favarell- Garrigues and Demarquez JL. Epidemiology of poisoning in children: a 7 -year survey in a paediatric emergency care unit. Eur J Emerg Med 2002;9:9-14.

19. Pillai GK, Boland K, Jagdeo S, Persad K. Acute poisoning in children. Cases hospitalized during a three- year period in Trinidad. West Indian Med J 2004;53(1): 50- 4.

20. Andiran N, Sarikayalar F. Pattern of acute poisonings in childhood in Ankara: what has changed in Twenty years? The Turkish J Pediatr 2004;46:147-52.

21. Asindi AA. Childhood Poisonings In: Azubuike JC, Nkanginieme KEO eds. Paediatric and Child health in a tropical region $2^{\text {nd }}$ edition African Educational services 2007;658-658.

22. Bjornass $M$, Jacobsen $D$, Haldorsen $T$, Ekeberg O. Mortality and Causes of death after hospital treated self- poisoning in Oslo: A 20 - year follow up. Clinical Toxicology 2009;47(2):116 -23.

23. Liisananti JH, Ala- Kokkot, Dunder TS, Ebeling HE. Contributing factors in self- poisoning leading to hospital admission in adolescents in Adolescents in Northern Finland. Substance use \& misuse 2010;45(9):1340-50. 
24. Steinhausen HC. Developmental psychopathology in adolescence: findings from a Swiss study The NAPE lecture 2005. Acta Psychiatr Scand 2006;113(1):6-12.

25. Buitelaar JK. Adolescence as a turning point for better and worse. Eur Child Adoles Psychiatry 2012;21(7):357-59.

26. Bellani M, Negri CA, Brambilla P. The days regulation profile in children and adolescents: a potential index for major psychopathology. Epidemiol Psychiatr Sci. 2012; 21(2):155-59.

27. Sylverken J. Home poisoning in children: More child poisoning cases recorded at KATH in Ghana. Lecture paper delivered at the 2005 annual general meeting of the Paediatric society of Ghana. Available at www.modernghana.com Retrieved $10 / 11 / 2014$.

28. Oluwadiya KS, Akinola EA. Taking alcohol by deception: an analysis of ethanol concentration of paraga an alcoholic herbal mixture in Nigeria. BMC Research Notes 2012;5:12.7

29. Obia E. Exploring the generator Economy! Will Nigeria Recover from Epileptic power supply? Available at www.bellanaija.com. Retrieved 10/ 01/2015.
30. Ganong WF. Respiratory adjustments in health and disease In: Foltin J, Nogueira I, Ransom J, Sheinis LA eds. Review of medical physiology $20^{\text {th }}$ ed. Lange medical Books/McGraw - Hill medical publishing Division USA. 2001;658-673.

31. Unintentional non- fire related carbon monoxide exposures: United States, 2001- 2003. Morbidity and Mortality weekly report, 2005;54: 36-39, 13132.

32. Household Ownership of GSM: Nigeria now has 83 million active GSM lines. Available at www. informationng.com Retrieved 15/12/2014.

33. Herbal medicine and related products registration and regulation 2005. Available at www.nafdac.gov. ng Retrieved 15/12/2014.

34. Obi E, Akunyili DN, Ekpo B, Orisakwe OE. Heavy metal hazards of a Nigerian herbal remedies. Sci Total Environ 2006;369:35-41.

35. WHO guidelines for assessing quality of herbal medicines with reference to contaminants and residues. Geneva: World Health Organisation 2007.

36. Persson HE, Sjoberg GK, Haines JA, Pronczuk de Garbino J. Poisoning severity score. Grading of acute poisoning. J Clin Toxicol 1998;36(3)205-21. 